\title{
Foodborne illnesses in Brazil: control measures for 2014 FIFA World Cup travellers
}

\author{
Ana Carolina Ritter ${ }^{1}$, Eduardo Cesar Tondo ${ }^{2}$ \\ ${ }^{1}$ Department of Agricultural and Food Sciences, University of Bologna, Bologna, Italy. \\ ${ }^{2}$ Food Science and Technology Institute, Federal University of Rio Grande do Sul, ICTA/UFRGS, Porto Alegre, \\ Brazil
}

\begin{abstract}
Foodborne diseases are typically caused by the ingestion of food contaminated with micro-organisms or their toxins, resulting in gastrointestinal disorders and in some severe cases hospitalization and death. In Brazil, foodborne illnesses are caused mainly by Salmonella, Staphylococcus aureus and Escherichia coli. The most important contributing factors for outbreaks are exposure of foods to unsuitable temperatures, inadequate food preparation and contamination of raw material or water used to prepare food. Recently, aiming to prevent foodborne illnesses during the 2014 FIFA World Cup, Brazil has developed a risk-based evaluation tool able to assess and grade Brazilian food services in cities that will host football matches. This tool has been used by the Brazilian sanitary surveillance officers during the inspection of facilities where food services. This is considered an innovative preventative sanitary action because it was created based on scientific information, statistical calculation and on risks of foodborne diseases occurrence. In this mini-review we summarize general data, control measures and how travellers can prevent foodborne illness in Brazil during the 2014 FIFA World Cup.
\end{abstract}

Key words: foodborne illnesses, Brazil, 2014 FIFA World Cup

J Infect Dev Ctries 2014; 8(3):254-257. doi:10.3855/jidc.4431

(Received 20 November 2013 - Accepted 30 January 2014)

Copyright (C) 2014 Ritter et al. This is an open-access article distributed under the Creative Commons Attribution License, which permits unrestricted use, distribution, and reproduction in any medium, provided the original work is properly cited.

\section{Foodborne illnesses worldwide}

In spite of all efforts for preventing foodborne illnesses around the world, these diseases remain an important public health concern worldwide [1,2]. Currently, there are approximately 250 agents of foodborne illness, which may be identified when one or more individuals show similar symptoms after ingestion of food contaminated with microorganisms or their toxins [3]. In the case of highly virulent food pathogens, such as Clostridium botulinum and Escherichia coli O157: H7, it is assumed that only one case can be considered as an outbreak [4].

The most common symptoms of foodborne illnesses are stomach pain, nausea, vomiting, diarrhea and, sometimes, fever. In most cases, the length of the symptoms may range from a few hours to more than five days, depending on the patient physical state, the type of microorganism, toxin ingested or the bacterial load in the food [5,6]. Most foodborne outbreaks have been related to the ingestion of food with normal appearance, taste and smell, without any apparent organoleptic alteration. This is because the infectious dose of food pathogens is usually lower than the amount of microorganisms required to spoil food. These facts complicate the traceability of contaminated food causing outbreaks, since affected consumers are usually not able to identify the food sources of infection. Furthermore, foods showing organoleptic alterations hardly cause foodborne outbreaks, because they are not consumed due to the repulsive feeling caused in consumers [4,5].

According to the Centers for Disease Control and Prevention (CDC), 48 million cases of foodborne illnesses are estimated to occur in the United States of America each year ( 1 in 6 Americans), resulting in 128,000 hospitalizations and 3,000 deaths [7]. In 2011 Scallan, et al. [2] have reported that $58 \%$ of foodborne illnesses in USA were caused by norovirus, followed by nontyphoidal Salmonella spp. (11\%), Clostridium perfringens (10\%) and Campylobacter spp. (9\%). Leading causes of hospitalization were nontyphoidal Salmonella spp. (35\%), norovirus (26\%), Campylobacter spp. (15\%), and Toxoplasma gondii $(8 \%)$, while the main causes of death were nontyphoidal Salmonella spp. (28\%), T. gondii (24\%), Listeria monocytogenes (19\%), and norovirus (11\%). 
In Europe, the European Food Safety Authority (EFSA) and the European Centre for Disease Prevention and Control reported the occurrence of 5,262 foodborne outbreaks in the European Union, comprising 43,473 human cases, 4,695 hospitalizations and 25 deaths, only in 2010. The main food sources were eggs, mixed or buffet meals and vegetables. Among the most frequent causative agents, Campylobacter continued to be the most reported agent, responsible for 212,064 confirmed human cases, followed by Salmonella $(99,020$ cases) and Yersinia enterocolitica (6,776 cases) [8].

Although food pathogens are still causing health problems in developed countries, in developing countries the situation may be more severe. In the latter, a considerable part of the population is more likely to suffer from foodborne illnesses, due to the lack of potable water for drinking and food preparation. Moreover the conditions for storage and transportation of foods are frequently inappropriate, and the lack of awareness regarding safe and hygienic food practices may be common [9]. However, due to the problem of sub-notification of cases, doubts about the exact number of foodborne diseases remain unclear in developed and in developing countries as well.

\section{Foodborne illnesses in Brazil}

Foodborne diseases control and prevention has improved considerably in Brazil in recent years. During the last two decades, many new food regulations have been launched. Good Manufacturing Practices (GMP) and Hazard Analysis and Critical Control Points (HACCP) have been implemented in several food industries and food services and the Sanitary and Epidemiological Surveillance Services are now better structured and prepared than before [4]. However, Brazil is still facing problems in controlling foodborne illnesses on its whole territory with a population of more than 195 million habitants. For instance, between 2000 and 2013, the Brazilian Ministry of Health has registered 8,857 foodborne outbreaks, 163,425 infected people and 112 deaths due to foodborne illnesses [10,11]. Even though these were the numbers officially reported, it is believed that the real number of foodborne cases is much higher. In fact, among the twenty-six Brazilian States, only few have consistent statistics and data published on the most common etiological agents and foods most frequently involved in foodborne outbreaks $[4,10]$. Most of the data on foodborne diseases are collected by the southeast and southern states of Brazil, i. e. the states of Rio Grande do Sul, São Paulo, Paraná, Santa Catarina, Rio de Janeiro and Minas Gerais, where active sanitary and epidemiological surveillance services have been implemented.

According to data of the Brazilian Ministry of Health, during the period between 2000 and 2013, Salmonella sp. was identified as the major causative agent of reported foodborne diseases (39.39\%), followed by Staphylococcus aureus (19.71\%), Escherichia coli (12.40\%), and Bacillus cereus $(7.62 \%) \quad[10]$. The etiological agents were not identified in $46.31 \%$ of the investigated foodborne diseases, mostly due to the lack of suspected food samples to investigate or because Brazilian official laboratories usually investigate only classical foodborne micro-organisms, but not emergent etiological agents. Based on official data, the most common food vehicles of foodborne diseases in Brazil were: 1) mixed food preparations, 2) eggs and eggbased products, 3) water, 4) sweets and desserts, 5) beef and processed red meat, 6) dairy products and 7) poultry. Private residences were the places most frequently associated with the occurrence of outbreaks, followed by food services, pastry shops and schools $[10,11]$.

\section{Epidemiological investigation of foodborne diseases outbreaks in Brazil}

In 1999, the Secretary of Surveillance of Health (SVS) of the Brazilian Ministry of Health, developed the National Surveillance Epidemiology of Foodborne Diseases System. This system was implemented in partnership with the National Agency of Sanitary Surveillance (ANVISA), Ministry of Agriculture, Livestock and Supply and the Pan-American Health Organization, aiming to reduce the incidence of foodborne outbreaks in Brazil [4,10]. Brazilian foodborne disease investigations are conducted by the Sanitary Surveillance Service of municipalities and the data collected by them are analyzed by the Epidemiological Surveillance Services of each city. It is important to note that Brazil has more than 5,500 cities and the organization of such structure is not an easy task. Highly severe outbreaks are also investigated by the Sanitary and Epidemiological Services of the Brazilian States, with are in charge of compiling outbreak data and inform the SVS in order to publish national official reports. Each State of Brazil has a Reference Laboratory that is responsible for the analyses of suspected food samples and stool samples from affected individuals. Suspected samples are collected during foodborne illnesses investigations 
and referred to the reference laboratories by the Sanitary and Epidemiological Surveillance officers. The number of officers depends on the size of the population of the cities, which may vary from some thousands to more than 15 million people, that is the case of São Paulo.

\section{Measures to prevent foodborne illnesses during 2014 FIFA World Cup in Brazil}

Brazil is expecting more than 3.5 million tourists for the FIFA World Cup in 2014 and it is estimated that more than 10 million extra meals will be served and consumed during this sportive event [12]. Aiming to prevent foodborne illnesses, Brazil has developed a risk-based evaluation tool able to assess and grade Brazilian food services of cities that will host football games. This tool has been used by the Brazilian sanitary surveillance officers during the inspections of food services, and it has been considered an innovative preventative sanitary action, because it, this food regulation was created strongly based on scientific information, statistical calculations and on the risks of occurrence of foodborne diseases. In order to achieve this goal, twenty-four Brazilian food safety-experts were invited to set up the tool and were asked to determine the likelihood of different food preparation situations that could lead to foodborne outbreaks. The opinion of the experts was based on scientific literature and on practical experiences during food inspection, audits and consulting. Subsequently, a draft of the evaluation tool was created and used to evaluate more than 500 food services located in ten Brazilian cities in order to test the adequacy of the tool. For each item of the tool a raw score was determined by the food safety-experts and adjusted based on the results of a factor analysis. The lowest raw score attributed by food safety-experts was 10 , and the highest score was 240. Loading factors ranging from 0.0001 to 0.6274 were calculated for each of the items. Using the evaluation instrument and based on the assigned scores, the overall scores of each food establishment was identified, ranging from 0 (when all items were in compliance with the tool) to 2,565.95 (when all items were inadequate), resulting in five classification categories according to their hygienic and sanitary conditions. This classification will be provided to the tourists and general population before the games, allowing them to choose adequate food establishments [12].

However, it is important for tourists to realize that, as for other big countries, Brazil presents a high diversity of hygienic conditions on its territory. For instance, while Brazil is the first poultry and beef exporter of the world, producing high quality and safe products, in many small cities the meat may be unsafe because is produced without respect for hygienic conditions and is commercialized without respect for refrigeration guidelines. While in big food producing companies the control measures of food safety management systems are put in practice routinely, in several restaurants, especially in small cities, food may be prepared under inadequate conditions. Based on these considerations, some practical advice to prevent foodborne diseases during a travel or during FIFA World Cup in Brazil is presented here.

\section{Water and drinks}

The majority of medium and big cities in Brazil are supplied with potable water, however the hygienic conditions in private water reservoirs of food services might vary considerably. Hotels, hostels kitchens and restaurants are supposed to clean and disinfect their water reservoirs every six months and assure that the water is potable. However, it is known that not all establishments follow this recommendation. In case of doubt, bottled drinks and mineral water are preferable, since these are usually produced under strict quality control systems. Freshly made fruit juices are usually safe in restaurants, but the general hygienic conditions should be considered by the customers. Drinks, ice and juices sold on the beach may present risks, because food services located on the beach may not be supplied with potable water. Therefore, drinks such as Caipirinha should be made with ice cubes packed into plastic bags produced by ice industries. Coconut water is one of the favourite drinks amongst tourists, but hygienic conditions of knives or other devices used to open the fruit should be considered.

Foods

Most of the Brazilian meat is safe. However, it is preferable to ask for well done poultry and red meat in restaurants. Some foodborne illnesses have been associated with meat products mainly due to inadequate control of temperature during storage or cooking [14].

Mix meals, as lasagna, feijoada, pastas, and other kind of foods served on buffets must to be consumed hot $\left(>60^{\circ} \mathrm{C}\right)$, while salads and fruits have to be served $<5^{\circ} \mathrm{C}$. All the restaurants in Brazil have to be in accordance with the limits established by the National Regulation RDC 216/2004 - ANVISA [14]. Avoiding homemade mayonnaise and products based on egg yolks is a safe practice, because of the potential risk of 
Salmonella contamination. In Brazil virtually industrial eggs are not contaminated with Salmonella. However, some restaurants may be still using nonindustrial eggs, produced without control [10]. In Brazil, lettuce salads or others leafy fresh vegetable products must be sanitized before consumption inside all food services, such as restaurants and hotels. Customers are recommended to ask if this procedure is carried out in the restaurant's kitchen. Products sold in supermarkets are generally safe, and industrialized foods are hardly involved in foodborne illnesses in Brazil. However, customers should pay attention to the refrigeration temperature of meats, cheese, ham, etc.

Seafood might pose a risk to consumers, because some foodborne diseases have been linked to them. Fresh seafood does not generally have contamination problems, but it is difficult for consumers to identify potential risks. To increase the chances of getting fresh and safe seafood, tourists should choose restaurants near the seashore and with a lot of customers. In such locations it is most probable that fresh seafood are used and rapidly consumed.

Fruit can be purchased from street vendors, but it should be washed thoroughly with potable water or the skin should be removed before eating. In case of need for health care assistance, travellers should contact the Brazil's healthcare system (Sistema Único de Saúde SUS) inside hospitals or use their private health insurance at any hospital.

\section{References}

1. WHO (2012) Reducing foodborne diseases by educating consumers. Geneva: World Health Organization. Available at: http://www.who.int/foodsafety/en/. Accessed 15 December 2013.

2. Scallan E, Hoekstra RM, Angulo FJ, Tauxe RV, Widdowson MA, Roy SL, Jones JL, Griffin PM (2011) Foodborne illness acquired in the United States-major pathogens. Emerg Infect Dis. Jan 17: 7-15.

3. Linscott, A. J. (2011). Food-Borne Illnesses. Clinical Microbiology Newsletter, 33: 41-45.

4. Oliveira ABA, Paula CMD, Capalonga R, Cardoso MRI, Tondo ED (2010) Doenças Transmitidas por Alimentos, Principais Agentes Etiológicos e Aspectos Gerais: uma revisão. Rev HCPA 30: 279-285.

5. Tondo EC, Bartz S (2012) Microbiologia e sistemas de gestão da segurança de alimentos, $1^{\text {st }}$ edition. Porto Alegre: Editora Sulina $263 \mathrm{p}$.
6. Pigott CD (2008) Fodborne Illness Emerg Med Clin N Am 26: 475-497.

7. Centers for Disease Control and Prevention. - CDC (2013) Estimates of Foodborne Illness in the United States. Available at: http://www.cdc.gov/foodborneburden/\# Accessed 25 november 2013.

8. EFSA Journal (2012) The European Union Summary Report on Trends and Sources of Zoonoses, Zoonotic Agents and Food-borne Outbreaks in 2010. 10: 2597

9. Saulat J (2012) Epidemiology of foodborne illness, Scientific, Health and Social aspects of the food industry, Dr. Benjamin Valdez (Ed), ISBN 978-953-307-916-5, In Tech, Available at: http://www.itechopen.com/books/scientific-health-and-socialaspects-of-the-food-industry/epidemiology-of-foodborneillness. Accessed 13 December 2013.

10. Brasil. Ministério da Saúde. Secretaria de Vigilância em Saúde- SVS. Dados Epidemiológicos- DTA- Período de 2001 a 2011. Available at http://www.saude.gov.br/svs . Accessed 11 January 2014.

11. Brasil. Ministério da Saúde. Secretaria de Vigilância em Saúde- SVS. Dados Epidemiológicos- DTA- Período de 2000 a 2013. Available at: www.saude.gov.br/svs. Accessed 11 January 2014.

12. Cunha DT, Oliveira ABA, Sacool ALF, Tondo EC, Junior EAS, Giani VC, Montesano FT, Castro AKF, Stedefeldt E (2014) Food safety of food services within the destinations 2014 FIFA World Cup in Brazil: development and reliability assessment of the official evaluation instrument. Food Research International. In press.

13. Tondo EC, Ritter AC Salmonella and Salmonellosis in Southern Brazil: A Review of the Last Decade (2012) In Monte, A.S. and De Santos, P.E. Salmonella: Classification, Genetics and Disease Outbreaks New York: Nova Science Publishers. 175-191.

14. Brasil (2004) Agência Nacional de Vigilância Sanitária. Resolução-RDC n. 216, de 15 de setembro de 2004 da. Dispõe sobre Regulamento Técnico de Boas Práticas para Serviços de Alimentação. Diário Oficial [da] República Federativa do Brasil, Brasília, DF, 16 set. 2004. Accessed 11 January 2014.

\section{Corresponding author}

Ana Carolina Ritter

Department of Agricultural and Food Sciences

University of Bologna, Bologna, Italy

Tel +390512086113

Fax +390512086113

Email: anacarolina.ritter@gmail.com

Conflict of interests: No conflict of interests is declared. 